\title{
Improving Student Success and Retention through a Summer Research Pro- gram for First and Second Year Students at a Minority-Serving Institution
}

\section{Dr. Melissa Danforth, California State University, Bakersfield}

Melissa Danforth is an Associate Professor and the Chair of the Department of Computer and Electrical Engineering and Computer Science at CSUB. Dr. Danforth is the PI for a NSF Federal Cyber Service grant (NSF-DUE1241636) to create models for information assurance education and outreach. Dr. Danforth is the Project Director for a U.S. Department of Education grant (P031S100081) to create engineering pathways for students in the CSUB service area. She is also the co-PI for an NSF IUSE grant for STEM retention (NSF-DUE 1430398) and the co-PD for multiple U.S. Department of Education grants related to engineering education and outreach. Her research interests are focused on network and system security, particularly with respects to protecting mission-critical resources and services. She is also conducting research in applying biological concepts to cybersecurity, such as artificial immune systems.

\section{Dr. Charles Lam, California State University, Bakersfield}

Dr. Charles C.Y. Lam is a Professor in the Department of Mathematics. Dr. Lam received his Ph.D. in Combinatorics and Optimization from the University of Waterloo. His research areas are in cryptography, digital watermarking, and combinatorics. He has extensive experience in curriculum assessment, undergraduate curriculum development, and student mentoring. 


\title{
(Work in Progress) Improving Student Success and Retention through a Summer Research Program for First and Second Year Students at a Minority-Serving Institution
}

\begin{abstract}
The effectiveness of undergraduate research programs on retention, graduation, and intention for graduate studies has been well-documented. Most of the programs focus on the undergraduate research experience among upper level college students. In this work in progress report, we focus on an undergraduate research program focusing primarily on first and second year students. Participants' attitude towards study in STEM, career options, and STEM awareness is measured, together with a one-year tracking in progress and retention.
\end{abstract}

\section{Introduction}

It is well studied that research experiences for undergraduates is an effective strategy in increasing the number of students who pursue degrees and careers in STEM fields (Tsui, 2007), and students are more likely to attend and complete graduate school (Bauer \& Bennett, 2003; Russell, Hancock, \& McCullough, 2007). Similar studies have been carried out among underrepresented minorities (Lopatto, Survey of undergraduate research experiences (SURE): first findings, 2004; Lopatto, Undergraduate research experiences support science career decisions and active learning, 2007; Pender, Domingo, Maton, \& Marcotte, 2010) with similar results. Most studies focused on a general undergraduate research program where participants are typically Juniors and Seniors who completed basic course work and were engaged in upper-level course work in the undergraduate curriculum. Little is known about the effects of summer exploratory / research work for lower-level undergraduate students.

California State University, Bakersfield (CSUB) holds designations as both a HSI and MSI. In year 2014, the university received a grant from the U.S. Department of Education Minority Science and Engineering Improvement Program (MSEIP). One activity sponsored under the grant is a summer research program for first and second year students who have completed the first year of their major coursework. The summer research program engages the students in realworld, applicable research through a four-week, all-day experience where students conduct research with university faculty members. The research is designed by the faculty members to be accessible to students who have only completed the first year of major coursework.

The goals of the program are to keep the students motivated and engaged with their major, to expose students to research in STEM, and to provide connections between the STEM major and STEM careers. First and second year students are targeted because the summers after the first year and second year of a STEM major are key intervention points for student success and retention. The program is modeled on prior works which have been shown to increase the retention and success of underrepresented minorities in STEM (Garcia-Otero \& Sheybani, 2012).

CSUB has run the summer program for the past two summers. In that time, ten faculty members have led research groups and fifty-nine undergraduate students participated in the research 
groups. Pre- and post-surveys were administered to the students. The surveys assess students' attitudes with respect to their interest in their field of study, their interest in a career in STEM, their preparation for the program, their awareness of the knowledge needed for a career in STEM, their awareness of the skills needed for a career in STEM, their awareness of what research in STEM is, and their interest in research in STEM. Forty-three students completed both the surveys.

\section{Program Activities}

Recruitment of students was conducted during the Spring of 2015 and 2016 through class visits, posters, and social media within the School of Natural Sciences, Mathematics, and Engineering (NSME) at the university. Student participants were given a stipend of $\$ 1500$ upon completion of the four-week program. Faculty mentors receive a stipend of $\$ 7000$ for a standalone program. In 2015, four engineering faculty incorporated the college participants with an ongoing high school four-week enrichment program sponsored by Chevron Corporation, where college and high school students participated in separate but related projects, and the faculty received a stipend of $\$ 1750$ each instead. Faculty participants can choose any consecutive four weeks within the summer for their program. The programs topics are listed in Tables 1 and 2.

Table 1: 2015 Summer Programs

\begin{tabular}{|l|l|}
\hline Discipline & Topic \\
\hline Biology & Research in Human Physiology \\
\hline $\begin{array}{l}\text { Computer } \\
\text { Science }\end{array}$ & Driving Enjoyment Detection from Video of the Frontal Face \\
\hline $\begin{array}{l}\text { Computer } \\
\text { Engineering }\end{array}$ & Home Energy Monitoring and Control System \\
\hline $\begin{array}{l}\text { Computer } \\
\text { Engineering }\end{array}$ & Coding and Decoding of Information in Mobile Communication \\
\hline $\begin{array}{l}\text { Engineering } \\
\text { Sciences }\end{array}$ & Study of Mechanical Behavior of Hydrocarbon-bearing Rocks \\
\hline $\begin{array}{l}\text { Engineering } \\
\text { Sciences }\end{array}$ & $\begin{array}{l}\text { Determination of Injection Well Location for Successful Enhanced Oil } \\
\text { Recovery }\end{array}$ \\
\hline Mathematics & Seasonal Effect of Air Pollution on Lung Disease \\
\hline
\end{tabular}

\section{Table 2: 2016 Summer Programs}

\begin{tabular}{|l|l|}
\hline Discipline & Topic \\
\hline $\begin{array}{l}\text { Engineering } \\
\text { Sciences }\end{array}$ & Smart and Automatic Irrigation System using Wireless Sensor Network \\
\hline $\begin{array}{l}\text { Engineering } \\
\text { Sciences }\end{array}$ & $\begin{array}{l}\text { Measurement of Oil-Water Interfacial Tension Using Microfluidic Y- } \\
\text { Junction }\end{array}$ \\
\hline $\begin{array}{l}\text { Geological } \\
\text { Sciences }\end{array}$ & Late Cenozoic Paleodrainage, Basin Boundary, and Landscape Evolution \\
\hline Physics & Wave-particle Duality of Light and the Photoelectric Effect \\
\hline
\end{tabular}




\section{Results and Analysis}

There were 25 participants in 2015 and 34 participants in 2016. Pre- and post-surveys were conducted to assess the effectiveness of the program. In addition, 2015 participants are tracked on retention in STEM. Among the 59 participants, 43 completed both pre- and post-surveys.

\section{Demographics of Participants}

Demographic data were collected in the pre-survey. Over two summers, 58\% (25/43) identify themselves as underrepresented minority (51.1\% Hispanic, 18.6\% White, $16.3 \%$ Asian, 7\% Black/African American, 7\% Two or More Races) while 35\% (15/43) are females. All but one participant had a chosen major before participating the program. The break down in gender and ethnicity is shown in Figure 1.

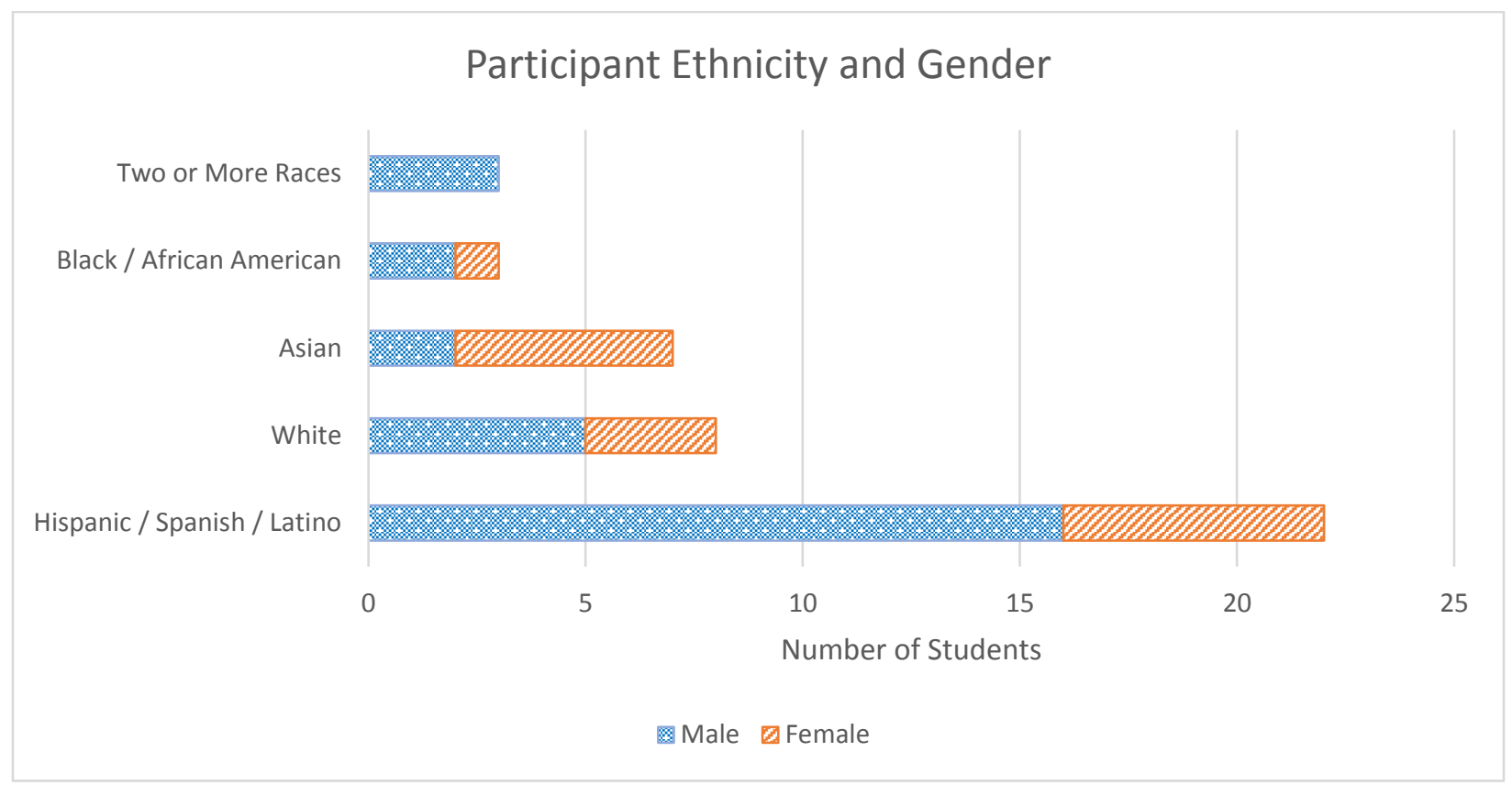

Figure 1: Participant Ethnicity and Gender

Participants' majors were tracked through registration data. Among the 59 participants, $63 \%$ (37/59) major in engineering, $15 \%$ in computer science or mathematics, and $22 \%$ in physical or life sciences.

\section{Trends from Surveys}

Survey questions are rated on a five-point Likert scale (1=strongly disagree, $3=$ neutral, $5=$ strongly agree). The survey questions were matched between the pre-survey and the postsurvey. The survey questions are intended to assess confidence and attitude towards STEM fields and research, as well as interest in STEM fields.

Respondents were required to indicate the level to which they agreed or disagreed to each statement. Minor, non-significant increases were observed in the following: interest in field of study (pre $=4.79$, post $=4.83$ ), interest in career in STEM (pre $=4.79$, post $=4.91$ ), preparedness of 
program (pre=4.23, post=4.74), knowledge in career in STEM (pre=4.56, post=4.86), understanding research in STEM (pre=4.23, post=4.72), interest in STEM research (pre=4.72, posy $=4.67)$. There is an observed decrease in understanding the skills required for a career in STEM (pre $=4.56$, post $=3.93$ ).

When individual responses are compared, there is no significant difference in change of attitude between the 2015 and the 2016 cohorts. The change in attitudes in described in Figure 2.

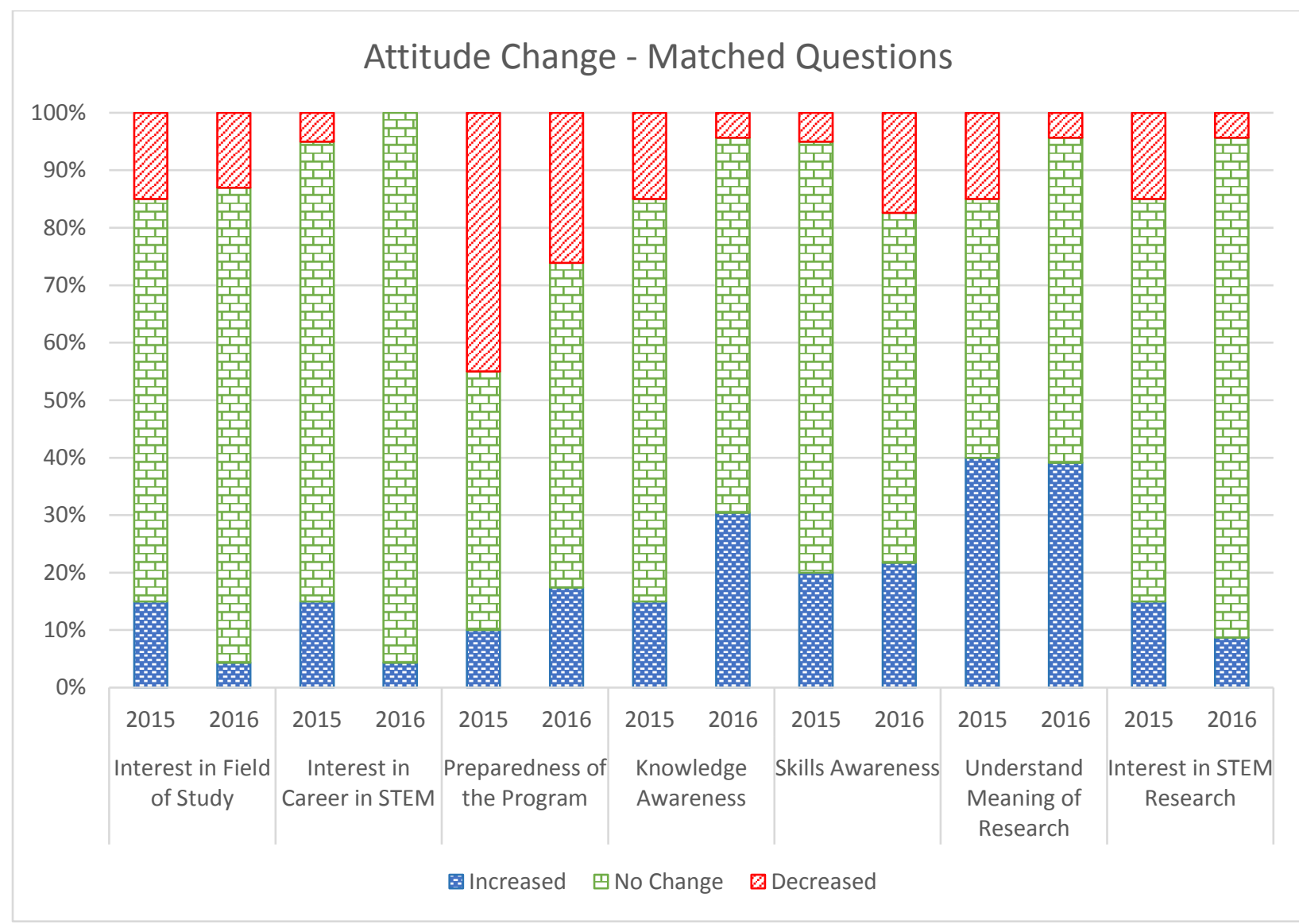

Figure 2: Change in Attitudes by Cohort

Since students all indicated high interest before entering the program, the post survey also inquired about their self-rated change in interest in their respective field of study, careers in STEM, and research in STEM. The majority of respondents reported an increase in interest in research in STEM, careers in STEM, and their respective field of study (Figure 3).

In the post-survey, participants were asked to provide open-ended feedback on what they liked about the program, what they would like to change the program, and any additional comments that they may have. The responses were overwhelmingly positive. Many students indicated that they enjoy the hands-on nature of the research projects, and that they would like to program to be longer. In the open-ended comments section, students expressed their gratitude for the opportunity and the experience. 


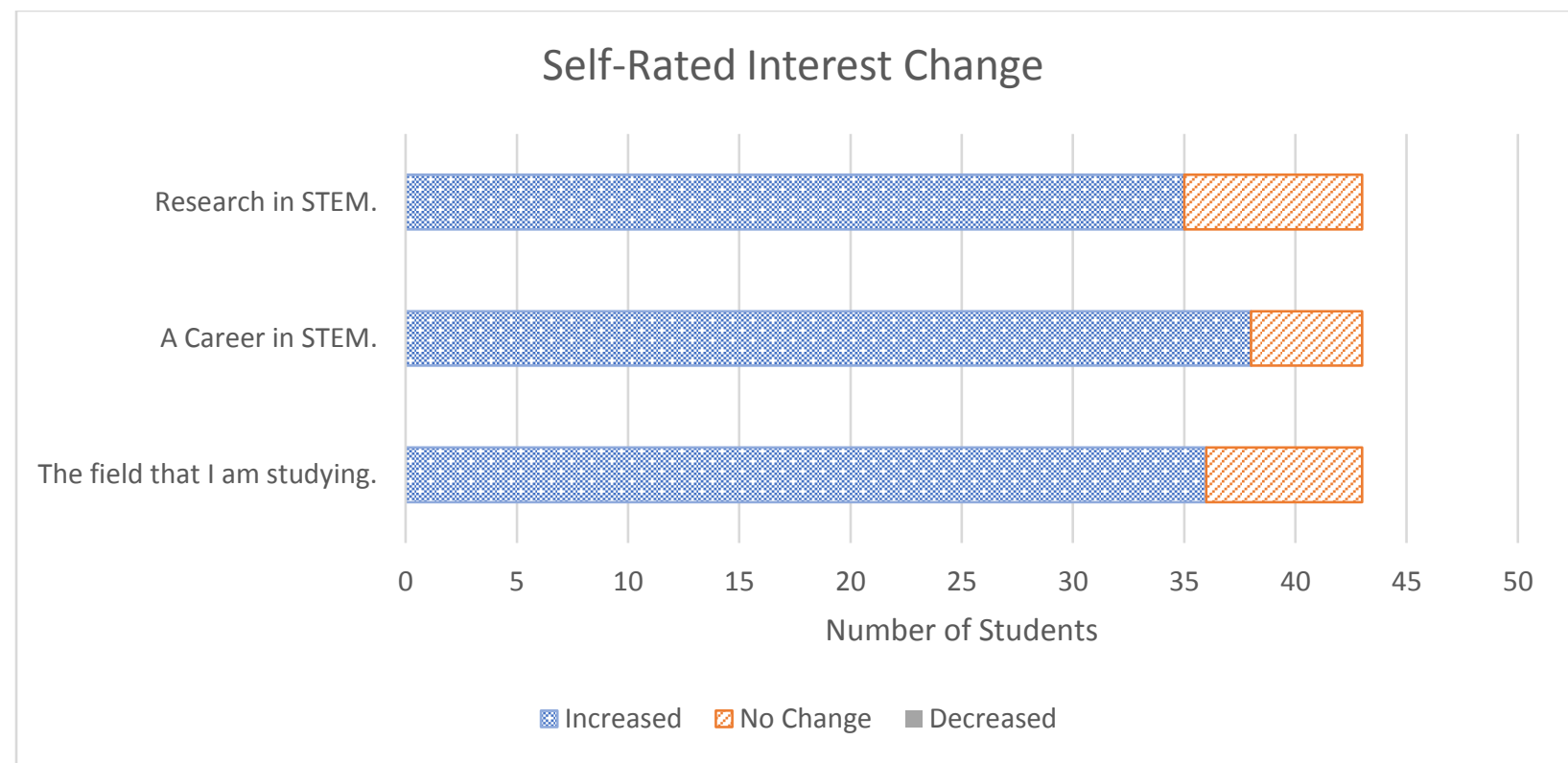

Figure 3: Change in Interest after Summer Research Program

\section{$\underline{\text { Retention in Major }}$}

Student participants from both years are tracked on academic progress. Year 1 students are tracked from Spring 15 (before program participation) through Spring 17. The number of college units that students completed at the application time ranged from 22 to 112 semester units, with a median of 33 semester units and an average of 45 semester units. The reason a student with 112 semester units was admitted was that the student changed majors into a STEM program and was considered a first-year STEM major due to course work. Out of 25 participants in the first year, one student graduated while two stopped enrollment. The retention / graduation rate is therefore $92 \%$. All students that are retained continued with their original major of choice. In Fall 16, the average participant has completed 88 semester units of course work.

Out of the 34 participants from the year two cohort, 33 (97\%) students are retained in the immediate Fall semester.

\section{Conclusion and Future Work}

The program has had a positive impact on student attitudes towards careers and research in STEM and has increased their awareness of the skills needed for success in STEM careers. However, students seem to be less confident in the skills that they need for a career in STEM after participating in research work. Further investigation is needed to determine the cause of the loss in confidence.

\section{Acknowledgement}

This material is based upon work supported by the Department of Education Minority Science and Engineering Improvement Program under Grant No. P120A140051. Any opinions, findings, 
and conclusions or recommendations expressed in this material are those of the author(s) and do not necessarily reflect the views of the Department of Education.

\section{Bibliography}

Bauer, K., \& Bennett, J. (2003). Alumni perceptions used to assess undergraduate research experience. The Journal of Higher Education, 74(2), 210-230.

Garcia-Otero, S., \& Sheybani, E. (2012). Retaining minority students in engineering: undergraduate research in partnership with NASA. American Society for Engineering Education Annual Conference. San Antonio: American Society for Engineering Education.

Lopatto, D. (2004). Survey of undergraduate research experiences (SURE): first findings. Cell Biology Education, 3(4), 270-277.

Lopatto, D. (2007). Undergraduate research experiences support science career decisions and active learning. CBE-Life Sciences Education, 6(4), 297-306.

Pender, M., Domingo, M., Maton, K., \& Marcotte, D. (2010). The STEM pipeline: the role of summer research experience in minority students' Ph. D. aspirations. Education Policy Analysis Archives, 18(30), 1-36.

Russell, S., Hancock, M., \& McCullough, J. (2007). Benefits of undergraduate research experiences. Science(Washington), 316(5824), 548-549.

Tsui, L. (2007). Effective strategies to increase diversity in STEM fields: a review of the research literature. The Journal of Negro Education, 555-581. 